\title{
Preoperative Pulmonary Evaluation and Evaluation of Postoperative Pulmonary Complications in Geriatric Patients Undergoing Spinal Surgery
}

\author{
Aydin Balci (Corresponding author) \\ Afyonkarahisar University of Health Sciences Medical Faculty \\ Hospital Chest Diseases Department in Turkey \\ Orcid: 0000-0002-6723-2418 \\ E-mail: draydnbalc@gmail.com \\ Usame Rakip \\ Afyonkarahisar University of Health Sciences, Faculty of Medicine, \\ Department of Neurosurgery in Turkey \\ E-mail: usamerakip@gmail.com \\ Akin Cengiz \\ Afyonkarahisar University of Health Sciences, Faculty of Medicine, \\ Department of Neurosurgery in Turkey \\ E-mail: usamerakip@gmail.com
}

\begin{abstract}
Background: The number of elderly (geriatric) population is increasing day by day and it becomes important in geriatric diseases and surgeries. It is predicted that approximately half of the population over the age of 65 will require surgical intervention during their lifetime in western societies in the following years. For this reason, he wanted to show that postoperative morbidity and mortality can be reduced with a careful preoperative pulmonary evaluation in this patient group, which we now encounter more frequently in pulmonology practice.
\end{abstract}

Objective: We aimed to examine the preoperative pulmonary risk assessment and the type of operation performed in geriatric patients who underwent spinal surgery, and its effect on postoperative complications and mortality in relation to the geriatric age group of the patient in the light of the literature.

Methods: Preoperative and postoperative consultations of 341 geriatric spinal surgery patients were retrospectively reviewed. Geriatric age group, gender, existing diseases, preoperative pulmonary risk class, type and duration of surgery, type of anesthesia (all patients were operated under general anesthesia), peroperative and postoperative complications were recorded.

Results: The mean age was $75.28 \pm 6.091$ (65-93). . When the patients with chronic disease in the preoperative period and died in the post-operative period were evaluated, a statistically significant difference was observed in the elderly group in terms of mortality rates in the presence of malignancy alone, COPD or CHF disease compared to other age groups. Postoperative respiratory complications were observed in $35(10.3 \%)$ patients. Respectively, 13 (3.81\%) patients had pneumonia, $12(3.51 \%)$ patients had atelectasis, $7(2.05 \%)$ patients had embolism, and $3(0.87 \%)$ patients had respiratory failure. There was a statistically significant increase in mortality rate in postoperative complications and death rates in direct proportion to age.

Conclusions: These complications can be minimized by better pulmonary preoperative risk assessment.

Keywords: Spinal surgery in geriatric patients, Preoperative pulmonary evaluation, Postoperative pulmonary risk

DOI: $10.7176 / \mathrm{JHMN} / 78-04$ 


\section{Özet}

Arka plan: Gün geçtikçe yaşlı(geriatrik) nüfus sayısı artmakta ve geriatri ile ilgili hastalıklar ve yapılan cerrahilerde önem kazanmaktadır. İlerleyen yıllarda batı toplumlarında 65 yaş üzeri nüfusun yaşamları süresince yaklaşık yarısının cerrahi müdahale ihtiyacı olacağı öngörülmektedir. Bu nedenle Günümüzde pulmonoloji pratiğinde artık daha fazla karşılaştığımız bu hasta grubunda, dikkatli bir preoperative pulmoner değerlendirme ile postoperatif morbidite ve mortalitenin azaltılabileceğini literature eşliğinde göstermek istedik.

Amaç: Spinal cerrahi uygulanan geriatrik hastalarda preoperatif pulmoner risk değerlendirmesi ve uygulanan operasyonun türü ile beraber hastanın geriatrik yaş grubu ile bağlantılı olarak postoperatif komplikasyonlar ve mortalite üzerine etkisini literatür eşliğinde incelemeyi amaçladık.

Yöntemler: 341 geriatrik spinal cerrahi hastasının preoperatif ve postoperatif konsültasyonları retrospektif olarak incelendi. Olguların geriatrik yaş grubu, cinsiyeti, mevcut hastalıkları, preoperatif pulmoner risk sınıfı, ameliyat tipi ve süresi, anestezi türü(tüm hastalar genel anestezi altında opere edilmiştir.), peroperatif ve postoperatif komplikasyonları kaydedildi.

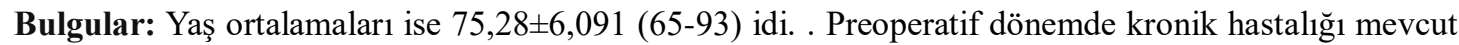
olup post operatif dönemde ölüm gerçekleşen hastalar değerlendirildiğinde ise tek başına malignite, KOAH veya KKY hastalığı varlığında ölüm oranları açısından ileri yaşlı grubunda diğer yaş gruplarına göre istatistiksel anlamlı fark izlendi. $35(\% 10,3)$ hastada ise postoperatif solunumsal komplikasyon görüldü. Sırası ile $13(\% 3,81)$ hastada pnömoni $12(\% 3,51)$ hastada atelektazi, $7(\% 2,05)$ hastada emboli ve $3(\% 0,87)$ hastada ise solunum yetmezliği izlendi. yaşla doğru orantılı olarak post operatif komplikasyon ve vefat oranlarında istatistiksel olarak ölüm oranı artışı mevcut idi.

Sonuçlar: daha iyi pulmoner preoperatif risk değerlendirilmesi ile bu komplikasyonların en aza indirilmesi sağlanabilir

Anahtar Kelimeler: Geriatrik hastalarda spinal cerrahi, Preoperative pulmoner değerlendrime, Post operatif pulmoner risk

\section{Giriş}

Yaşlanma; organizmanın hücre, doku ve sistemler düzeyinde zamanla ortaya çıkan, geri dönüşü olmayan, fonksiyonel ve yapısal değişikliklerin tümünü kapsayan fizyolojik bir süreçtir (1). Yaşlanma süreci doğumla birlikte başlar ve her çeşit organizma doğumundan ölümüne kadar çok sayıda değişikliğe uğrayarak yaşlanır.

Dünya Sağlık Örgütü (DSÖ)'nün 1998'de yaşlılıkla ilgili olarak yayınladığı sağlık raporuna göre yaşlılık; özürlülüklerin artması ve başkalarına daha çok bağımlı olma şeklinde tanımlanmış ve yaşlılık sınırı 65 yaş olarak belirlenmiştir(2). Demografik açıdan yaşlılık şu şekilde sınıflandırılmaktadır; Genç (Erken) Yaşlılık: 65-74 yaş arasını kapsar. Bu dönem sıklıkla emeklilik sonrası dönemdir.

Orta Yaşlılık: 75-84 yaş arasını kapsar. Bu dönemde sıklıkla işlevsel kayıplar görülmeye başlanır, ancak kişi çoğunlukla tek başına yaşamını sürdürebilir.

İleri Yaşlılık: 85 yaş ve üzerini kapsar. Bu dönemde kişiler, ailelerinin veya özel bakım veren kurumların yardıma ihtiyaç duyarlar.(3)

Gün geçtikçe yaşlı(geriatrik) nüfus sayısı artmakta ve geriatri ile ilgili hastalıklar ve yapılan cerrahilerde önem kazanmaktadır. İlerleyen yıllarda batı toplumlarında 65 yaş üzeri nüfusun yaşamları süresince yaklaşık yarısının cerrahi müdahale ihtiyacı olacağı öngörülmektedir(4). Bu artışın yanı sıra yaşlı nüfusta cerrahi sonrası komplikasyonlar ve uzamış hastane yatış süresi genç nüfusa göre daha fazla görülmektedir(5). 65 yaş ve üzeri nüfusta multipl kronik hastalıklarda sık görülmektedir(6). Artmış yaş ile birlikte organ fonksiyonlarındaki fizyolojik değişimler, yandaş hastalıkların ve kırılganlık, sarkopeni gibi geriatrik sendromların varlığı postoperatif komplikasyonların primer sebepleri olarak gösterilmektedir(5). Bu durumlar beraberinde çoklu ilaç kullanımını getirmekte ve ilaç etkileşimleri sonucu perioperatif dönemde yan etkilerde artış olmaktadır(7). Günümüzde pulmonoloji pratiğinde artık daha fazla karşılaştığımız bu hasta grubunda, dikkatli bir preoperatif değerlendirme ile postoperatif morbidite ve mortalitenin azaltılabileceğini, hastane maliyetinde düşüş sağlanabileceğini bildiren çalışmalar artmıştır( 8,9$)$. Bu tür çalışmalar iyi bir preoperatif değerlendirmenin özgeçmiş, fiziksel ve mental durum değerlendirmesini, preoperatif testleri ve risk sınıflamasını içermesi gerektiğini vurgulamaktadır (7) Bu hastalarda postoperatif pulmoner komplikasyon riskini belirlemek amacıyla rutin olarak preoperatif spirometre ve gögüs radyografisi istenmeyebilir, fakat kronik

28 | $P$ a g e

www.iiste.org 
obstrüktif pulmoner hastalık veya astım öyküsü olan hastalarda bu tetkikler faydalı olabilir (10) Yaşlı nüfus ve ilerleyen yaşla birlikte cerrahi gerektiren hastaların artışına bağlı olarak bu hasta grubunda preoperatif pulmoner değerlendirmede verilen riske göre post operatif ortaya çıkan komplikasyonlar giderek daha fazla önem kazanmaktadır. Bütün bu veriler kalitenin arttırılması ve komplikasyonların en aza indirilmesi amacıyla ameliyat olması planlanan geriatrik hastalar için stratejiler geliştirilmesinin önemini ortaya koymaktadır.

Biz de bu çalışmamızda spinal cerrahi uygulanan geriatrik hastalarda preoperatif pulmoner risk değerlendirmesi ve uygulanan operasyonun türü ile beraber hastanın geriatrik yaş grubu ile bağlantılı olarak postoperatif komplikasyonlar ve mortalite üzerine etkisini literatür eşliğinde incelemeyi amaçladik.

\section{Gereç Ve Yöntem}

Çalışmaya 2014-2019 yılları arasında Afyonkarahisar Sağlık Bilimleri Üniversitesi Tıp Fakültesi Hastanesi nöroşirürji kliniğinde opere edilen 870 hastadan 341 geriatrik spinal cerrahi hastası dahil edildi. Geriatrik cerrahi hastaların preoperatif konsültasyon verileri ve postoperatif konsültasyonları retrospektif olarak incelendi. Olguların geriatrik yaş grubu, cinsiyeti, mevcut hastalıkları, preoperatif pulmoner risk sınıfı, ameliyat tipi ve süresi, anestezi türü(tüm hastalar genel anestezi altında opere edilmiştir.), peroperatif ve postoperatif komplikasyonları kaydedildi.

\section{1 İstatistiksel Analiz}

İstatistiksel analiz için SPSS Wındows 20 programı kullanıldı. Çalışma verilerini değerlendirmek için tanımlayıcı istatistiksel yöntemler (ortalama, standart sapma, medyan, frekans, oran, minimum, maksimum) kullanıldı. Kantitatif verilerin normal dağılıma uygunluğu Kolmogorov-Smirnov, Shapiro - Wilk testi ve grafiksel değerlendirmelerle test edilmiştir. İki grup kantitatif veri normal dağılımla karşılaştırılmasında Student- $t$ testi, iki veri grubunun normal olmayan dağılımla karşılaştırılmasında Mann-Whitney $U$ testi kullanıldı. Niteliksel verileri karşılaştırmak için Pearson Ki-Kare testi ve Fisher's Exact testi kullanıld1. Anlamlılık $p<0.05$ olarak belirlendi

\subsection{Etik Onay}

Çalışma için Afyonkarahisar Sağlık Bilimleri Üniversitesi 2020/49(2011-KAEK2) sayılı etik kurul onayı alınmıştır.

\section{Bulgular}

Araştırmaya alınan hastaların 146(\%42,8)'sı erkek ve 195(\%57,2)'i kadın idi. Yaş ortalamaları ise $75,28 \pm 6,091$ (65-93) idi. Katılımcılarımız geriatrik yaş gruplarına göre sinıflandırdığımızda $165(\% 48,4)$ ü erken yaşl1, 146(\%42,8)'sı orta yaşlı ve $30(\% 8,8)$ 'u ileri yaşlı hastalardan oluşuyordu. Hastaların 94( \%27,6) ‘̈ aktif sigara içicisiydi. Preoperatif pulmoner değerlendirilen hastaların muayene sırasındaki saturasyon değerleri 94(62-90), nabız değerleri ise 80(42-163)/dakika olarak ölçüldü. Saturasyon değerleri ileri geriatrik yaş grubu ile diğer iki geriatrik grup arasında istatistiksel olarak farklı idi $(\mathrm{p}<0,001)$ Tablo 1 de geriatrik yaş gruplarına göre demografik özellikler verilmiştir Hastaların $148(\% 43,4)$ 'inde en az bir kronik hastalık mevcut idi. En sık görülen kronik hastalıklar ise sirası ile 70(\%20,5) hastada esansiyel hipertansiyon (HT) ve kroner arter hastalı̆̆ $1(\mathrm{KAH}), 47(\% 13,7)$ hastada kronik solunum hastalıkları (Astım ve kronik obstrüktif akciğer hastalı̆̆ vb), 45(\%13,2) hastada diyabetes mellitus (DM), mevcut idi. Geriatrik yaş grupları kendi aralarında kıyaslandığında toplam kronik hastalıklar açısından istatistiksel olarak anlamlı fark izlenmedi. Preoperatif dönemde kronik hastalığı mevcut olup post operatif dönemde ölüm gerçekleşen hastalar değerlendirildiğinde ise tek başına malignite, KOAH veya KKY hastalığı varlığında ölüm oranları açısından ileri yaşlı grubunda diğer yaş gruplarına göre istatistiksel anlamlı fark izlendi. (Sırası ile p:0,013, 0,024, 0,015) Tablo 2' de Geriatrik Yaş gruplarına göre kronik hastalık sıklı̆̆ı verilmiştir.

Hastalara uygulanan spinal cerrahi operasyon çeşitlerine göre bakıldığında en sık $89(\% 26,1)$ kişiye vertebral fraktür operasyonu yapılırken sonrasında $86(\% 25,2)$ hasta ile spinal darlık operasyonu ve $77(\%$ 22,6) hasta ile disk herniasyonu operasyonu gerçekleştirilmiş idi. Postoperatif mortalite oranları açısından bakıldığında ise cerrahi girişimler ve yapılan cerrahi bölge farklılıklarına rağmen komplikasyon ve ölüm oranları açısından istatistiksel olarak anlamsız idi $(p=0,094)$. Tablo 3 geriatrik hastalara uygulanan spinal cerrahi uygulamaları ve uygulanan geriatrik yaş aralığ 1 verilmekte. 
Tablo1. Geriatrik Yaş gruplarında ve totalde geriatrik hastaların demografik özellikleri

\begin{tabular}{|c|c|c|c|c|c|c|c|c|c|}
\hline & \multicolumn{2}{|c|}{ Erken Yaşlilık } & \multicolumn{2}{|c|}{ Orta Yaşlı } & \multicolumn{2}{|c|}{ İleri Yaşı } & \multicolumn{2}{|c|}{ Total } & \multirow[t]{2}{*}{$\mathrm{P}$} \\
\hline & $\mathrm{n}=165$ & $\% 48,4$ & $\mathrm{n}=146$ & $\% 42,8$ & $\mathrm{n}=30$ & $\% 8,8$ & $\mathrm{n}=34$ & $\% 100$ & \\
\hline Yaş & \multicolumn{2}{|c|}{$70,1 \pm 2,67$} & \multicolumn{2}{|c|}{$78,72 \pm 2,70$} & \multicolumn{2}{|c|}{$87 \pm 1,81$} & \multicolumn{2}{|c|}{$75,28 \pm 6,09$} & $\mathrm{P}<0,001$ \\
\hline \multicolumn{10}{|l|}{ Cinsiyet } \\
\hline Kadın & 87 & $\% 47,3$ & 90 & $\% 61,6$ & 18 & $\% 60$ & 195 & $\% 57,2$ & \multirow{2}{*}{0,270} \\
\hline Erkek & 78 & $\% 52,7$ & 56 & $\% 38,4$ & 12 & $\% 40$ & 146 & $\% 48,2$ & \\
\hline Kronik Hastalık & 76 & $\% 46,1$ & 62 & $\% 42,5$ & 10 & $\% 33,3$ & 148 & $\% 43,4$ & 0,481 \\
\hline Sigara & 53 & $\% 32,1$ & 31 & $\% 21,2$ & 10 & $\% 33,3$ & 94 & $\% 27,6$ & 0,076 \\
\hline Ortalama Yatış Gün & \multicolumn{2}{|c|}{$11(2-134)$} & \multicolumn{2}{|c|}{$11(1-86)$} & \multicolumn{2}{|c|}{$13(1,31)$} & \multicolumn{2}{|c|}{$11(1-134)$} & 0,973 \\
\hline Satürasyon & \multicolumn{2}{|c|}{$95(80-99)$} & \multicolumn{2}{|c|}{ 94(78-99) } & \multicolumn{2}{|c|}{$90,5(62-99)$} & \multicolumn{2}{|c|}{$94(62-99)$} & $P<0,001$ \\
\hline Nabız/Dakika & \multicolumn{2}{|c|}{$80(42-163)$} & \multicolumn{2}{|c|}{$80(47-116)$} & \multicolumn{2}{|c|}{$81(60-117)$} & \multicolumn{2}{|c|}{$80(42-163$} & 0,393 \\
\hline
\end{tabular}

Tablo 2. Geriatrik Yaş gruplarına göre kronik hastalık oranları

\begin{tabular}{|c|c|c|c|c|c|c|c|c|c|}
\hline & \multicolumn{2}{|c|}{$\begin{array}{c}\text { Erken Yaşl1 } \\
n=165\end{array}$} & \multicolumn{2}{|c|}{$\begin{array}{c}\text { Orta Yaşl1 } \\
n=146\end{array}$} & \multicolumn{2}{|c|}{$\begin{array}{c}\text { İleri Yaşl1 } \\
\mathrm{n}=30\end{array}$} & \multicolumn{2}{|c|}{$\begin{array}{c}\text { Total } \\
\mathrm{n}=341\end{array}$} & \multirow[t]{2}{*}{$\mathrm{p}$} \\
\hline & $\mathrm{n}$ & $\% 48,4$ & $\mathrm{n}$ & $\% 42,8$ & $\mathrm{n}$ & $\% 8,8$ & $\mathrm{n}$ & $\%$ & \\
\hline $\begin{array}{l}\text { Hipertansiyon Ve Kroner } \\
\text { Arter Hastalığ } 1\end{array}$ & 42 & $\% 25,5$ & 23 & $\% 15,8$ & 5 & $\% 16,7$ & 70 & 20,5 & 0,092 \\
\hline Diyabet & 25 & $\% 15,2$ & 17 & $\% 11,6$ & 3 & $\% 10,0$ & 45 & 13,2 & 0,570 \\
\hline $\begin{array}{l}\text { Kronik obstrüktif akciğer } \\
\text { hastalığı }\end{array}$ & 15 & $\% 9,1$ & 8 & $\% 5,1$ & 1 & $\% 3,3$ & 24 & 7 & 0,654 \\
\hline Astım & 10 & 6,1 & 10 & 6,8 & 3 & $\% 10$ & 23 & 6,7 & 0,730 \\
\hline Konjestif kalp yetmezliği & 9 & 5,5 & 7 & 4,8 & 1 & 3,3 & 17 & 5 & 0,878 \\
\hline Nörolojik Hastalık & 2 & 1,2 & 7 & 4,8 & 0 & 0 & 9 & 2,6 & 0,093 \\
\hline Tiroid fonksiyon Bozukluğu & 5 & 3 & 3 & 2,1 & 1 & 3,3 & 9 & 2,6 & 0,840 \\
\hline Malignite & 6 & 3,6 & 6 & 4,1 & 0 & 0 & 12 & 3,5 & 0,535 \\
\hline Benign prostat hipertrofisi & 2 & 1,2 & 4 & 2,7 & 0 & 0 & 6 & 1,8 & 0,442 \\
\hline Kronik böbrek yetmezliği & 3 & 1,8 & 2 & 1,4 & 1 & 3,3 & 6 & 1,8 & 0,755 \\
\hline Osteoporoz & 3 & 1,8 & 1 & 0,7 & 0 & 0 & 4 & 1,2 & 0,536 \\
\hline
\end{tabular}


Tablo 3. Geriatrik Hasta gruplarına uygulanan uygulanan spinal cerrahi sayıları

\begin{tabular}{|c|c|c|c|c|c|c|c|c|c|}
\hline & & $\begin{array}{l}\text { Yaşl11ık } \\
165\end{array}$ & & $\begin{array}{l}\text { Yaşl1 } \\
146\end{array}$ & & $\begin{aligned} & \text { Yaşlı } \\
= & 30\end{aligned}$ & & & $\mathrm{P}$ \\
\hline & $\mathrm{n}$ & $\% 48,4$ & $\mathrm{n}$ & $\% 42,8$ & $\mathrm{n}$ & $\% 8,8$ & $\mathrm{n}$ & $\%$ & \\
\hline Spinal darlık & 42 & 25,5 & 39 & 26,7 & 5 & 16,7 & 86 & 25,2 & \\
\hline Disk Hernisi & 41 & 24,8 & 32 & 21,9 & 4 & 13,3 & 77 & 22,6 & \\
\hline Vertebral Fraktür & 37 & 22,4 & 40 & 27,4 & 12 & 40 & 89 & 26,1 & 0,732 \\
\hline Vertebral Kitle & 15 & 9,1 & 12 & 8,2 & 4 & 13,3 & 31 & 9,1 & \\
\hline Vertebra Enfeksiyonu & 15 & 9,1 & 11 & 7,5 & 3 & 10 & 29 & 8,5 & \\
\hline Sistem Revizyonu & 15 & 9,1 & 12 & 8,2 & 2 & 6,7 & 29 & 8,5 & \\
\hline
\end{tabular}

Tablo 4. Geriatrik hasta gruplarına göre preop verilen risk ve post operatif komplikasyonlar.

\begin{tabular}{|c|c|c|c|c|c|c|c|c|c|}
\hline & \multicolumn{2}{|c|}{$\begin{array}{c}\text { Erken Yaşl111k } \\
\mathrm{N}=165(\% 48,4)\end{array}$} & \multicolumn{2}{|c|}{$\begin{array}{c}\text { Orta Yaşl1 } \\
\mathrm{N}=146(\% 42,8)\end{array}$} & \multicolumn{2}{|c|}{$\begin{array}{c}\text { İleri Yaşlı } \\
\mathrm{N}=30(\% 8,8)\end{array}$} & \multicolumn{2}{|c|}{$\begin{array}{c}\text { Total } \\
\mathrm{N}=341\end{array}$} & \multirow[t]{2}{*}{$\mathrm{P}$} \\
\hline & $\mathrm{n}$ & $\%$ & $\mathrm{n}$ & $\%$ & $\mathrm{n}$ & $\%$ & $\mathrm{n}$ & $\%$ & \\
\hline \multicolumn{10}{|l|}{ Preop Verilen Risk } \\
\hline Hafif & 11 & 6,7 & 3 & 2,1 & 0 & 0 & 14 & 4,1 & \multirow{5}{*}{$\mathrm{P}<0,001$} \\
\hline Hafif-Orta & 27 & 16,4 & 21 & 14,4 & 1 & 3,3 & 49 & 14,4 & \\
\hline Orta & 83 & 50,3 & 59 & 40,4 & 8 & 26,7 & 150 & 44 & \\
\hline Orta-Ağır & 22 & 13,3 & 27 & 18,5 & 8 & 26,7 & 57 & 16,7 & \\
\hline Ağır & 22 & 13,3 & 36 & 24,7 & 13 & 43,3 & 71 & 20,8 & \\
\hline \multicolumn{10}{|l|}{ Hastaneye Başvuru Durumu } \\
\hline Normal & 137 & 83 & 124 & 84,9 & 22 & 73,3 & 283 & 83 & \multirow{3}{*}{0,387} \\
\hline Acil & 19 & 11,5 & 18 & 12,3 & 5 & 16,7 & 42 & 12,3 & \\
\hline Trafik Kazası & 9 & 5,5 & 4 & 2,7 & 3 & 10 & 16 & 4,7 & \\
\hline \multicolumn{10}{|l|}{ Yattığı Bölüm } \\
\hline Servis & 156 & 94,5 & 136 & 93,2 & 23 & 76,7 & 315 & 92,4 & \multirow{2}{*}{0,003} \\
\hline Yoğun bakım & 9 & 5,5 & 10 & 6,8 & 7 & 23,3 & 26 & 7,6 & \\
\hline $\begin{array}{l}\text { Post Operatif Solunumsal } \\
\text { Komplikasyon }\end{array}$ & 13 & 7,9 & 13 & 8,9 & 9 & 30 & 35 & 10,3 & 0,001 \\
\hline \multicolumn{10}{|l|}{ Taburculuk Tipi } \\
\hline Şifa İle & 125 & 78,8 & 117 & 80,1 & 18 & 60 & 260 & 76,3 & \multirow{3}{*}{0,004} \\
\hline Hali İle & 34 & 20,6 & 17 & 11,6 & 6 & 20 & 57 & 16,7 & \\
\hline Vefat & 6 & 3,6 & 12 & 8,2 & 6 & 20 & 24 & 7 & \\
\hline
\end{tabular}


Geriatrik hastaların preoperatif pulmoner değerlendirmelerine bakıldığında tüm hastalara posteroanterior akciğer (PA-AC) garafisi istenmiş ve PA-AC garafisinde $218(\% 63,9)$ Hastanın normal bulgular $118(\% 34,6)$ hastanın sekel değişiklikler ve $5(\% 1,5)$ soliter pulmoner nodül veya malignite ile uyumlu görüntüsü mevcut idi. Fizik muayenelerinde $12(\% 3,51)$ hastanın ronküsü ve $11(\% 3,22)$ hastada ral mevcut idi. $8(\% 2,34)$ hastada kronik solunum yetmezliği nedeni Uzun süreli oksijen tedavisi kullanımına bağlı nazal oksijenli saturasyon takibi yapılıyordu. Hastalara verilen preoperatif riskler değerlendirildiğinde $150(\% 44)$ hastaya orta risk verilirken $71(\% 20,8)$ hastaya ağır risk verilmiş idi. Hastalara verilen riskler değerlendirildiğinde hastalara verilen risklere göre geriatrik yaş ilerledikçe hastaya verilen riskte de artış olduğu olduğu değerlendirildi $(\mathrm{P}<0,001)$.

Hastaneye başvuru durumları değerlendirildiğinde geriatrilk hastaların 283(\%83)'ü poliklinik başvuru yaparken 58(\%17)'i acil servis başvurusu şeklinde gerçekleşmiştir. Acil servis başvuruları içersinden ise $16(\% 4,7)$ kişide araç içi trafik kazası nedeni ile başvurmuştur. Trafik kazası ve acil operasyon nedeni ile başvuran hastalarda elektif opere edilen hastalara göre istatistiksel ölüm oranı fazla idi $(\mathrm{P}=0,015)$ Operasyon sonrası hastaların 315(\%92,4)'i nöroşirürji servisinde yatarken 26(\% $\%, 6)$ 's1 yoğun bakımda tedavi görmüştür. $(\mathrm{P}<0,001)$ Tedavi gören hastaların 24 ü ise postoperatif komplikasyonlar nedeni ile vefat etmiş olup bunlardan 12 si post operatif pulmoner komplikasyonlar nedeni ile vefat etmiş idi. $(\mathrm{P}<0,001) 35(\% 10,3)$ hastada ise postoperatif solunumsal komplikasyon görüldü. Sırası ile $13(\% 3,81)$ hastada pnömoni $12(\% 3,51)$ hastada atelektazi, $7(\% 2,05)$ hastada emboli ve $3(\% 0,87)$ hastada ise solunum yetmezliği izlendi. Emboli geçiren hastalardan ise $1(\% 0,29)$ i vefat etmiş idi. Ayrıca yoğun bakım yatışı olan hastalarda yatış süresi uzadıkça mortalitede artış görüldü. $(\mathrm{p}<0,001)$

Hastane yatış gün sayısındaki artış ile emboli geçirme arasında pozitif kolelasyon mevcut idi ( $p$ $=0,034)$. Geriatrik hasta grupları arasındaki post operatif komplikasyonlara bağlı ölüm oranları ise yaşla doğru orantılı olarak post operatif komplikasyon ve vefat oranlarında istatistiksel olarak ölüm oranı artışı mevcut idi(sırası ile p: 0,001, 0,004) tablo 4. Geriatrik hasta gruplarına göre preop verilen risk ve post operatif komplikasyonlar.

\section{Tartışma}

Geriyatrik hastalarda; yaşlanmaya eşlik eden fizyolojik değişiklikler, preoperatif risklerin artmasına ve postoperatif komplikasyonların gelişmesine neden olabilir [11]. Geriatrik hastalarda preoperatif değerlendirmede amaç operasyon sırasında veya sonrasında oluşabilecek komplikasyonlara aday hastaları belirlemektir. Bu hastalarda perioperatif riskleri arttıran faktörler; hızlı gelişen ve geri dönüşü yavaş olan ilerleyici fonksiyonel düşüş, yandaş hastalıkların genç ve yetişkinlere göre daha fazla görülmesi ve bu hastalarda ilaçlara, anestezi ve cerrahiye karşı gelişebilecek beklenmedik reaksiyon sıklığının yüksek olmasıdır [12]. Postoperatif dönemde en fazla mortalite ve morbiditeye neden olanlar komplikasyonlar ise pulmoner komplikasyonlardır (13). Cerrahi öncesinde yapılan değerlendirmelerde yaş mevhumunun uygunluğu için karar verme aşamasında bir kriter olarak uygun olup olmadığı aslında tartışmalıdır. Bundan dolayıdır ki ne kadar ileri yaş olursa olsun geriyatrik hastalara da başarılı bir şekilde anestezi vermek ve onları hastalık öncesi dönemlerine döndürmek olasıdır [14]. Geriyatrik hastalarda postoperatif morbidite ve mortalite riskini arttıran faktörler değerlendirildiğinde ise yüksek preoperatif pulmoner risk oranı, yüksek anestezi preoperatif risk değeri ,operasyonun acil operasyonlar arasında olması, major vasküler operasyon olması, uzun süreli-yüksek kan ve sıvı kaybı beklenen cerrahiler, eşlik eden kronik hastalıklar (kardiyak, pulmoner, renal, hepatik, DM, vb.), malnutrisyon, yatalak olmak veya bakım desteğinin olmamasıdır. Günümüzde preoperatif pulmoner değerlendirme çoğunlukla; varolan komorbiditeler; egzersiz toleransı, bazı laboratuvar tetkikleri, fizik muayene ve laboratuvar bulguları ile yapılan değerlendirmelerin hiçbiri geriyatrik hastalara özel değildir. Bu nedenlede klinisyenin kendi pratiğinde geliştirdiği pratik, klinikle beraber hastaların fizik muayeneleri ve bulgularına göre oluşturduğu bir preoperatif risk skalası mevcuttur. Preoperatif anamnezde değerlendirilmesi gereken diğer parametreler; yaş, sigara ve ilaç öyküsü, mesleki maruziyet, immobilizasyon, eşlik eden hastalıklar ve pulmoner emboli risk faktörleridir. Ayrıca uyku-apne semptomları, yeni geçirilmiş solunum yolu enfeksiyonu varlığı sorgulanmalıdır. Detaylı bir değerlendirme ile önceden tanımlanmayan bir akciğer hastalığına ait bulgular elde edilebilmekte ve cerrahi öncesi bazal durumun belirlenmesinde yardımcı olabilmektedir $(15,16)$. Geriyatrik hasta gruplarında, kardiyak ya da pulmoner sorunu olanlarda, postoperatif pulmoner komplikasyon için yüksek risk grubunda olanlara mutlaka preoperatif dönemde akciğer grafisi önerilmektedir (17) 19661993 yılları arasında yapılan 21 adet çalışmanın değerlendirildiği daha eski bir meta-analizde ise $(n=14390)$ vakaların \%10'unun akciğer grafisinde anormallik saptanmış ve sadece \% 0.1 'inin tedavi edilmesi gerekmiştir (18). Özellikle yeni veya açıklanamayan semptom ve bulguların varlığında, alttaki

32 | P a g e 
mevcut hastalığın semptom ve bulgularında ani kötüleşme saptandığında veya toraks cerrahisi uygulanacaksa preoperatif dönemde akciğer grafisi çekilmesi yararlıdır (19) Çalışmamızda da hastaların tama yakınına preoperatif dönemde PAAC grafileri değerlendirilmiş ve operasyona engel bir durum saptanılmamıştır. Ayrıca çalışmamız değerlendirildiğinde hastaların çoğundan solunum fonksiyon testi(SFT) istenmediğinden dolayı SFT testi değerlendirilme dişı bırakılmıştır. Zaten yakın zamanda yapılan bir çalışmada da preoperatif solunum fonksiyon testi değerlerinin postoperatif komplikasyon riskini öngörmediği saptanmıştır (20).

Çeşitli yayın ve farklı cerrahi girişimlere bağlı vaka serilerinde postoperatif pulmoner komplikasyonların sıklığ1 \%6-79 arasında değişmektedir.[14, 21-26] Bu geniş aralığın muhtemel nedeni çalışmalardaki cerrahi hastalarının farklı cerrahi girişimlere maruz olmaları ve çalışmalardaki postoperatif pulmoner risk ölçütlerinin faklı oluşlarıdır. Literatürde geriatrik hasta gruplarında yapılmış olan spinal cerrahi sonrası postoperatif pulmoner komplikasyon oranları ile ilgili çalışma sayıları çok azdır. Yakın zamanda yapılmış bir çalışmada Chun DH. ve arkadaşlarının 217 hastalık retrospektif spinal operasyon serisinde Spinal cerrahi için toplam komplikasyon oranlarına bakılmış ve bu oran \% 22.6 olarak bulunmuş. Ve ortaya çıkan komplikasyonlarda Hematom, derin enfeksiyon, plevral efüzyon, halsizlik ilerlemesi, pulmoner ödem, özofagus yaralanması , miyokard enfarktüsü, pnömoni , yeniden ameliyat dahil olarak sınıflandırılmış ve bu komplikasyonlara bağlıda böbrek yetmezliği, sepsis ve ölüm meydana geldiği bildirilmiştir.(27) Weinberg DS. ve ark retrospektif olarak spinal cerrahi uygulanan 302 hastalık çalışmalarındaki post operatif pulmoner komplikasyonlar değerlendirildiğinde ise $47(\% 15,56)$ hastada post operatif pulmoner komplikasyon görüldüğü bildirilmiş ve bunlar sırası ile 35 kişide pnömoni, 10 kişide erişkin solunum sıkıntısı sendromu (ARDS) ve 2 kişide pulmoner emboli idi. Ayrıca çalışmalarında Pulmoner komplikasyonları önemli ölçüde daha uzun hastanede kalışlar ve yoğun bakım ünitesinde kalmaya bağlı olduğunu ifade ekmektelerdi. (28) En önemli postoperatif pulmoner komplikasyonlar; ise sırası ile atelektazi, pnömoni, solunum yetmezliği ve kronik akciğer hastalığının alevlenmesidir(10). Benzer şekilde Çalışmamızda postoperatif solunumsal komplikasyon oranı 35(\%10,3) civarındaydı ve en sik solunumsal komplikasyonlar sırası ile pnömoni onun ardından atelektazi ve pulmoner emboli idi. Pnömoni ve pulmoner emboli komplikasyonları benzer çalışmalarda oluğu gibi hastane yatışı uzayan ve yoğun bakım yatışı devam eden hastalarda mortal seyretmiş olup istatistiksel olarakta anlamlı idi. Pnömoni oranları literatür ile uyumlu idi hastaların ortalama operasyon süreleri ise literatürden kısa fakat yaş ortalamalarının yüksek olması nedeni ile komplikasyon oranlarında operasyon süreleri kısa olsada artış olduğu düşünülebilir . Pulmoner komplikasyonlar spinal cerrahisi geçiren yetişkin hastalar için ciddi bir morbidite ve mortalite kaynağıdır. Postoperatif pnömoni için,> 70 yaş, sigara öyküsü, kronik obstrüktif akciğer hastalığı, yetersiz beslenme, dental plaklar, uzun ameliyat süresi, gastrik tüpler ve enteral beslenme, torasik / ön yaklaşımlar ve uzun süreli immobilizasyon gibi çeşitli risk faktörleri tanımlanmıştır. (29) bizim çalışmamızda da pulmoner komplikasyonlrdan meydana gelen vefat oranları ise $12(\% 3,5)$ olup totalde pulmoner koplikasyonlarında dışında vefat oranı $24(\% 7)$ bulunmuştur Postoperatif dönemdeki pnömoni koplikasyonlarını, operasyondan önce preoperatif değerlendirme ile risk faktörlerini ele alarak en aza indirilebilir.çalımamızda da preoperatif risk değerlendirilmesi sonucu yüksek ve orta yüksek risk verilen hastalarda daha fazla solunumsal komplikasyon geliştiği ve bununda pulmoner preoperatif değerlendirmenin önemini gösterdiği aşikardır.

Platzer P. ve arkadaşlarının spinal cerrahi geçiren yetişgin hastalarda yaptıkları retrospektif çalışmalarında Ameliyat prosedürlerinin ortalama uzunluğu 4,5 (2-9) saat idi ve 171 (\% 18) hastada postoperatif komplikasyonlar görüldü. Ortalama hastanede kalış süresi 37 (11-163) gündü. Spinal cerrahi sonrası 36(\% 4) postoperatif komplikasyonlara bağlı öldü. Spinal cerrahi sonrası 22 hastada (\% 2.2) semptomatik tromboembolik komplikasyon gelişti. Tromboembolik komplikasyonlar yaşlı hastalarda ve erkeklerde ve ayrıca düzenli sigara içen veya obezite şikayeti olan hastalarda daha sık görüldü.(30)Patader ve arkadaşlarının 361 spinal cerrahi uygulanan yetişkin hastada yaptıkları retrospektif bir çalışmada pte oranını $10(\% 2,4)$ hasta olarak bulmuşlar ve ayrıca farmakolojik dmah proflaksisinin spinal cerrahi yapılan hastalarda pte gelişimini azalttığı öngörüsüne varmışlar idi(31)Bizim çalışmamızda Ortalama hastanede kalış süresi 11 (1-134) tüm hastalarda PTE(pulmoner tromboemboli) proflaksisi almalarına rağmen komplikasyon olarak 7 hastada pte görülmüş ve komplikasyon olarak 3 hastada ölüm gerçekleşmiştir. ölüm oranları literatürle aynı olsada pte komplikasyon ornları geriatrik hastalar olmasından dolayı fazla bulunmuştur. 


\section{Sonuç}

Sonuç olarak değerlendirildiğinde bütün cerrahi operasyonlar sonrasında Pulmoner komplikasyonlar, yaşamı tehdit eden en önemli komplikasyonlar arasında yer almakta ve giderek artan geriatrik nüfus tada dahada önem kazanmaktadır. Ayrıca farklı cerrahi türlerinde preoperatif değerlendirme ve sonrasında kestirilebilir ve önlenebilir pulmoner komplikasyonların bilinmesi önemlidir. Çalışmamızda da spinal cerrahi sonrası geriatrik hastaların post operatif pulmoner komplikasyonlarını ve geriatri bilimi ile alakasını ortaya koymaya çalıştık ve geriatrik hastalarda yaş grupları arttıkça hastalarda meydana gelen koplikasyon ve ölüm oranlarının arttığı gördük. Bu nedenden dolayıdır ki ilerleyen dönemlerde daha iyi pulmoner preoperatif risk değerlendirilmesi ile bu komplikasyonların en aza indirilmesi sağlanabilir.

\section{Kaynaklar}

[1] Saddock BJ, Saddock VA. Klinik Psikiyatri. Aydın H, Bozkurt A, çeviri editörleri. Klinik Psikiyatri. 8. Bask1. Ankara: Güneş Kitabevi; 2007. s. 3595-602.

[2] Kutsal YG. Temel Geriatri. İstanbul: Güneş Tıp Kitapevleri; 2007.

[3] Bozcuk N, Demirsoy A. Yaşlanmanın Biyolojisi. Kutsal YG, Çakmakçı M, Ünal S, editörler. Geriatri. Ankara: Hekimler Yayın Birliği; 1997. s. 23-7.

[4] Murray D, Dodds C. Pre-operative Assessment of the Elderly. BJA CEPD Reviews 2001;1(6): 181-4

[5] Partridge JSL, Harari D, Martin FC, Dhesi JK.Preoperative Comprehensive Geriatric Assessment. Anaesthesia 2014; 69(1): 8-16

[6] Salive EM. Multimorbidity in Older Adults. Epidemiol Rev 2013; 35(1):75-83

[7] Cook DJ, Rooke GA. Priorities in Perioperative Geriatrics. Anesth Analg 2003; 96: 1823-36

[8] Manku K, Bacchetti P, Leung J. Prognostic Significance of Postoperative In-Hospital Complications in Elderly Patients. I. Long Term Survival. Anesth Analg 2003; 96: 583-9

[9] Harari D, Hopper A, Dhesi J, Babic-Illman G, Lockwood L, Martin F. Proactive Care of Older People Undergoing Surgery('POPS'): Designing, Embedding, Evaluating and Funding a Comprehensive Geriatric Assessment Service for Older Elective Surgical Patients. Age and Ageing 2007; 36: 190- 6

[10] Smetana GW, Conde MV. Preoperative pulmonary update.Clin Geriatr Med 2008; 24: 60724.

[11] Ersoy A, Çakırgöz M, Türkmen Ü. Geriyatrik anestezi. Okmeydanı Tıp Dergisi 2013;29:1069. http://dx.doi.org/10.5222/otd.supp2.2013.106

[12] Bettelli G. Preoperative evaluation in geriatric surgery: comorbidity, functional status and pharmacological history. Minerva Anestesiol 2011;77:637-46.

[13] Lawrence VA, Dhanda R, Hilsenbeck SG, Page CP. Risk of pulmonary complications after elective abdominal surgery. Chest 1996;110:744-50.

[14] Edwards AE, Seymour DG, McCarthy JM, Crumplin MK. A 5-year survival study of general surgical patients aged 65 years and over. Anaesthesia 1996;51: 3-10. http://dx.doi. Org /10. 1111/j.1365-2044.1996.tb07645.x

[15] Erdinç E. Preoperatif Pulmoner Değerlendirme. TTDO Mesleki Gelişim Kursu. 2007:24-7.

[16] Zamani A. Preoperatif Pulmoner Değerlendirme, TTD Kitapları. 2006:7-16.

34 | P a g e

www.iiste.org 
[17] Doyle RL. Assessing and modifying the risk of postoperative pulmonary complications. Chest 1999;115:77-81.

[18] Archer C, Levy AR, McGregor M. Value of routine preoperative chest x-rays: a metaanalysis. Can J Anasesth 1993;40:1022-7.

[19] Anonymous. A rational approach to radiodiagnostic investigations. World Health Organ Tech Rep Ser 1983;689:1-49.

[20] Kroenka K, Lawrence VA, Theroux JF, Tuley MR. Operative risk in patients with severe obstructive pulmonary disease. Arch Intern Med 1992;152:967-71.

[21] Goldman L, Caldera DL, Nussbaum SR, Southwick FS, Krogstad D, Murray B, et al. Multifactorial index of cardiac risk in noncardiac surgical procedures. N Engl J Med 1977;297:845-50. http://dx.doi.org/10.1056/NEJM197710202971601

[22] Gupta PK, Franck C, Miller WJ, Gupta H, Forse RA. Development and validation of a bariatric surgery morbidity risk calculator using the prospective, multicenter NSQIP dataset. J Am Coll Surg 2011;212:301-9. http://dx.doi.org/10.1016/j.jamcollsurg.2010.11.003

[23] Lee TH, Marcantonio ER, Mangione CM, Thomas EJ, Polanczyk CA, Cook EF, et al. Derivation and prospective validation of a simple index for prediction of cardiac risk of major noncardiac surgery. Circulation 1999;100:1043-9. http://dx. doi.org/10 .1161 /01. CIR.100.10.1043

[24] Fleisher LA, Beckman JA, Brown KA, Calkins H, Chaikof E, Fleischmann KE, et al. ACC/AHA 2007 guidelines on perioperative cardiovascular evaluation and care for noncardiac surgery: executive summary: a report of the American College of Cardiology/American Heart Association Task Force on Practice Guidelines (Writing Committee to Revise the 2002 Guidelines on Perioperative Cardiovascular Evaluation for Noncardiac Surgery). Anesth Analg 2008;106:685-712. http://dx.doi.org/10.1213/01/ane.0000309024.28586.70

[25] Qaseem T. Risk assessment for and strategies to reduce perioperative pulmonary complications. Ann Intern Med 2006;145:553. http://dx.doi.org/10.7326/0003-4819-145-7200610030-00017

[26] Burgos E, Gómez-Arnau JI, Díez R, Mu-oz L, Fernández-Guisasola J, Garcia del Valle S. Predictive value of six risk scores for outcome after surgical repair of hip fracture in elderly patients. Acta Anaesthesiol Scand 2008;52:125-31. http://dx.doi.org/10.1111/j.13996576.2007.01473.x

[27] Chun DH, Kim DY, Choi SK, et al. Feasibility of a Modified E-PASS and POSSUM System for Postoperative Risk Assessment in Patients with Spinal Disease. World Neurosurg. 2018;112:e95-e102. doi:10.1016/j.wneu.2017.12.092

[28] Weinberg DS, Hedges BZ, Belding JE, Moore TA, Vallier HA. Risk factors for pulmonary complication following fixation of spine fractures. Spine J. 2017;17(10):1449-1456. doi:10 .1016/j.spinee.2017.05.008

[29] Brooks JA. Postoperatif nozokomiyal pnömoni: hemşireye duyarlı müdahaleler. AACN Clin Sorunlarl 2001; 12: 305-23.

[30] Platzer P, Thalhammer G, Jaindl M, et al. Thromboembolic complications after spinal surgery in trauma patients. Acta Orthop. 2006;77(5):755-760. doi:10.1080/17453670610012944

[31] APA Pateder, Dhruv B., MD ; Gonzales, Ricardo A., MD ; Kebaish, Khaled M., MD ; Antezana, David F., MD ; Cohen, David B., MD, MPH ; Chang, Jen-Yi, MD ; Kostuik, John P., MD Yetişkin Spinal Deformit Cerrahisi Sonrası Pulmoner Emboli, Omurga: 1 Şubat 2008 Cilt 33 - Say1 3 - s 301-305 doi: 10.1097 / BRS.0b013e31816245e1 